\title{
ВMJ Global Health Decomposing the rural-urban gap in factors associated with childhood immunisation in sub-Saharan Africa: evidence from surveys in 23 countries
}

\author{
Edward Kwabena Ameyaw (D) , ${ }^{1}$ Yusuf Olushola Kareem, ${ }^{2}$ \\ Bright Opoku Ahinkorah (D) , ${ }^{1}$ Abdul-Aziz Seidu (D) , ${ }^{3,4}$ Sanni Yaya (D) 5,6
}

To cite: Ameyaw EK,

Kareem Y0, Ahinkorah B0, et al. Decomposing the rural-urban gap in factors associated with childhood immunisation in sub-Saharan Africa: evidence from surveys in 23 countries. BMJ Global Health 2021;6:e003773. doi:10.1136/ bmjgh-2020-003773

Handling editor Seye Abimbola

- Additional material is published online only. To view please visit the journal online (http://dx.doi.org/10.1136/ bmjgh-2020-003773)

Received 20 August 2020 Revised 21 November 2020 Accepted 19 December 2020

Check for updates

(c) Author(s) (or their employer(s)) 2021. Re-use permitted under CC BY-NC. No commercial re-use. See rights and permissions. Published by BMJ.

For numbered affiliations see end of article.

Correspondence to

Dr Sanni Yaya;

sanni.yaya@uottawa.ca

\section{ABSTRACT}

Background About 31 million children in sub-Saharan Africa (SSA) suffer from immunisation preventable diseases yearly and more than half a million children die because of lack of access to immunisation. Immunisation coverage has stagnated at $72 \%$ in SSA over the past 6 years. Due to evidence that full immunisation of children may be determined by place of residence, this study aimed at investigating the rural-urban differential in full childhood immunisation in SSA.

Methods The data used for this study consisted of 26241 children pooled from 23 Demographic and Health Surveys conducted between 2010 and 2018 in SSA. We performed a Poisson regression analysis with robust Standard Errors (SEs) to determine the factors associated with full immunisation status for rural and urban children. Likewise, a multivariate decomposition analysis for non-linear response model was used to examine the contribution of the covariates to the observed rural and urban differential in full childhood immunisation. All analyses were performed using Stata software V.15.0 and associations with a $\mathrm{p}<0.05$ were considered statistically significant.

Results More than half of children in urban settings were fully immunised (52.8\%) while $59.3 \%$ of rural residents were not fully immunised. In all, $76.5 \%$ of rural-urban variation in full immunisation was attributable to differences in child and maternal characteristics. Household wealth was an important component contributing to the rural-urban gap. Specifically, richest wealth status substantially accounted for immunisation disparity $(35.7 \%)$. First and sixth birth orders contributed $7.3 \%$ and $14.9 \%$, respectively, towards the disparity while $7.9 \%$ of the disparity was attributable to distance to health facility.

Conclusion This study has emphasised the rural-urban disparity in childhood immunisation, with children in the urban settings more likely to complete immunisation. Subregional, national and community-level interventions to obviate this disparity should target children in rural settings, those from poor households and women who have difficulties in accessing healthcare facilities due to distance.

\section{Key questions}

What is already known?

- Immunisation coverage in sub-Saharan Africa has stagnated at $72 \%$ over the past 6 years.

- Approximately 31 million children in sub-Saharan Africa are at risk of immunisation preventable diseases each year.

What are the new findings?

- $76.5 \%$ rural-urban variation in full immunisation in sub-Saharan Africa is attributable to differences in child and maternal characteristics.

- No child aged 11-23 months from Zimbabwe was fully immunised.

What do the new findings imply?

- Subregional, national and community-level interventions to obviate rural-urban disparity in immunisation should target rural children as well as those in poor households and women who have difficulties in accessing healthcare facilities due to distance. Factors mediating the large gap need to be considered by immunisation interventions.

\section{BACKGROUND}

Globally, significant decline in under-5 mortality has occurred especially between 1970 and 2016 and this has been partly attributed to childhood immunisation. ${ }^{1-3}$ Childhood immunisation constitutes one of the most impactful and cost-effective public health interventions. ${ }^{4}$ It is efficacious in attenuating infectious disease-related ill health and deaths among children. ${ }^{4}$ Childhood immunisation has been acknowledged as a prerequisite for achieving target 3.2 of the Sustainable Development Goals (SDGs), thus achieving neonatal mortality of 12 per 1000 live births and under-5 mortality of 25 per 1000 live births by $2030 .^{5}$ Yet, as of 2016, estimates revealed that one in five African children went unimmunised. ${ }^{6}$ About 31 million 
children in sub-Saharan Africa (SSA) suffer from immunisation preventable diseases yearly and more than half a million die as a result of lack of access to immunisation. ${ }^{7}$ Immunisation coverage has stagnated at $72 \%$ in SSA over the past 6 years. ${ }^{7}$ In spite of these, the benefits of immunisation to the well-being of children are enormous. Moreover, several countries in Africa are unable to reach and immunise most vulnerable children in rural and remote locations. ${ }^{8}$

In recent times, studies have explored the predictors and barriers to immunisation or full immunisation while series of reviews have been conducted on this subject. Some of these recent studies have reported that lack of knowledge of immunisation, lack of partner support, financial deprivation and distrust in immunisation programmes account for incomplete or nonimmunisation. ${ }^{9-11}$ Further evidence indicate rural-urban variation in childhood immunisation in some parts of $\mathrm{SSA}^{12}$ while another study examined rural-urban variations in missed opportunities of immunisation in SSA, ${ }^{13}$ and showed an emerging trend in the disparity in favour of urban residents. It is, therefore, not unanticipated that under-5 mortality is higher among rural children compared with urban children in SSA. ${ }^{14}$

A greater segment of health workforce in SSA are also concentrated in urban settings ${ }^{15}$ and this could increase the prospects of urban children to receive full immunisation at the expense of those in rural locations. This situation incontestably hampers the prospects of achieving Universal Health Coverage of full childhood immunisation and increase chances of childhood mortalities. Populations in difficult terrains and rural settings are highly disadvantaged, encounter setbacks in healthcare access as well as participating in preventive interventions and may have less prospects of achieving full immunisation coverage. ${ }^{15}$

In spite of the foregoing, there is limited scholarly research that collate data from several countries on the magnitude of rural-urban disparity in full immunisation in SSA. There is, therefore, the need to decompose immunisation by rural-urban variations in order to deepen the depth of knowledge on childhood immunisation in SSA. As a result, we investigated the rural-urban differences in childhood immunisation among children 12-23 months in SSA. The findings from this study are anticipated to enhance current knowledge and guide the development of result-oriented interventions for childhood immunisation within the subregion.

\section{METHODS}

\section{Data source}

We sourced data from the most recent Demographic and Health Surveys (DHS) of 23 countries conducted between 2010 and 2018. These 23 countries were included based on two principal reasons: countries having DHS data within the study period (ie, from 2010 to 2018) and comparability of data due to availability of required variables within the datasets. These surveys were executed by the DHS Programme. DHS is executed in low-income and middle-income countries in partnership with local organisations in the respective countries. It is usually conducted at 5-year interval and follows a common execution procedure. The survey focuses on crucial maternal and child health factors such as immunisation, maternal healthcare utilisation, malaria and other essential indicators. ${ }^{16}$ A two-stage stratified sampling procedure is adopted in selecting research participants. In the first phase, clusters/enumeration areas (EAs) are selected guided by a sample frame developed during the preceding census of the respective countries, while in the second stage, a sample of households is drawn from each selected EAs. The full sampling procedure has been documented elsewhere. ${ }^{16}$ A total of 26241 children who had complete information on all the variables considered were eligible for this study. We relied on the Strengthening the Reporting of Observational Studies in Epidemiology statement in conducting this study and writing the manuscript (online supplemental file 1).

\section{Measurement of variables}

Outcome variable

Full immunisation coverage of children 12-23 months was the outcome of interest. Children within 12-23 months are expected to receive the rudimentary immunisation dosages. Following the WHO recommendations, a child was considered to be fully immunised if the child has received Bacille Calmette-Guerin against tuberculosis; at least three doses of polio vaccine; three doses of diptheria, tetanus toxoids and pertussis vaccine and one dose measles vaccine ${ }^{17}$ as illustrated in table 1 . Subsequently, a child between 12 and 23 months who had received all nine doses was classified as fully immunised (coded 1), while any child without all the dosages was categorised as non-fully immunised (coded 0$)$.

\section{Independent variables}

The key independent variable was residential status, that is, rural or urban area. Based on some immunisation literature,${ }^{911} 13$ we selected and controlled for nine (9) covariates grouped into child factors: sex of child, and birth order as well as maternal factors: maternal age, education, wealth quintile, occupation, sex of household head, health insurance subscription status and distance

\begin{tabular}{ll}
\hline Table 1 Recommended immunisation for SSA children \\
\hline At birth & BCG; Polio 0 \\
\hline 6 weeks period & Polio 1; DPT 1 \\
10 weeks period & Polio 2; DPT 2 \\
14 weeks period & Polio 3; DPT 3 \\
9 months period & Measles \\
\hline
\end{tabular}

Source: modified from WHO. ${ }^{17}$

BCG, Bacille Calmette-Guerin; DPT, Diphtheria-Pertussis-Tetanus; SSA, sub-Saharan Africa. 
Table 2 Details and summaries of countries' immunisation status by residence

\begin{tabular}{|c|c|c|c|c|c|}
\hline \multirow[b]{2}{*}{ Countries } & \multirow[b]{2}{*}{ Year of survey } & \multirow[b]{2}{*}{ Sample size } & \multicolumn{2}{|c|}{ Prevalence of full Immunisation } & \multirow[b]{2}{*}{$P$ value } \\
\hline & & & Urban prev. $(95 \% \mathrm{Cl})$ & Rural prev. $(95 \% \mathrm{Cl})$ & \\
\hline Benin & $2017 / 2018$ & 2382 & $60.2(56.1$ to 64.1$)$ & 53.1 (49.7 to 56.4$)$ & 0.008 \\
\hline Burundi & 2016 & 1236 & 78.7 (67.3 to 87.0$)$ & 77.8 (74.8 to 80.5$)$ & 0.862 \\
\hline $\begin{array}{l}\text { Democratic } \\
\text { Republic of Congo }\end{array}$ & $2013 / 2014$ & 1661 & 42.3 (36.4 to 48.5$)$ & 22.8 (18.7 to 27.6$)$ & $<0.001$ \\
\hline Ethiopia & 2016 & 1813 & 49.0 (36.4 to 61.7$)$ & $12.8(10.2$ to 16.1$)$ & $<0.001$ \\
\hline Gabon & 2012 & 726 & 3.9 (2.2 to 6.6$)$ & 9.0 (5.9 to 13.6$)$ & 0.013 \\
\hline Ghana & 2014 & 562 & $67.5(60.1$ to 74.1$)$ & 55.6 (48.1 to 62.9$)$ & 0.024 \\
\hline Gambia & 2013 & 715 & 65.5 (56.1 to 73.9$)$ & 84.9 (81.0 to 88.2$)$ & $<0.001$ \\
\hline Guinea & 2018 & 717 & 25.5 (18.7 to 33.6$)$ & 17.2 (13.6 to 21.5$)$ & 0.041 \\
\hline Kenya & 2014 & 1815 & $69.3(62.1$ to 75.7$)$ & 54.9 (51.3 to 58.5$)$ & $<0.001$ \\
\hline Liberia & 2013 & 665 & 49.2 (37.3 to 61.2) & 43.3 (37.2 to 49.5$)$ & 0.394 \\
\hline Lesotho & 2014 & 109 & 87.8 (70.2 to 95.7$)$ & 65.9 (52.3 to 77.4$)$ & 0.033 \\
\hline Mali & 2018 & 1803 & 44.5 (37.7 to 51.6$)$ & $31.4(27.7$ to 35.4$)$ & 0.001 \\
\hline Malawi & $2015 / 2016$ & 1073 & 56.0 (43.8 to 67.5 ) & 55.7 (51.6 to 60.0$)$ & 0.961 \\
\hline Nigeria & 2018 & 1278 & 45.7 (39.8 to 51.7 ) & 23.0 (19.5 to 26.9$)$ & $<0.001$ \\
\hline Niger & 2012 & 970 & 71.0 (64.4 to 76.7$)$ & 37.5 (33.1 to 42.0$)$ & $<0.001$ \\
\hline Namibia & 2013 & 404 & 75.5 (66.7 to 82.6 ) & 84.6 (79.6 to 88.5$)$ & 0.038 \\
\hline Sierra Leone & 2013 & 943 & 63.2 (54.5 to 71.2 ) & 67.5 (62.6 to 72.1$)$ & 0.380 \\
\hline Togo & $2013 / 2014$ & 689 & 67.4 (59.5 to 74.4$)$ & 56.5 (49.4 to 63.3 ) & 0.040 \\
\hline Tanzania & $2015 / 2016$ & 2006 & 75.9 (71.7 to 79.6$)$ & 47.6 (43.4 to 51.8$)$ & $<0.000$ \\
\hline Uganda & 2016 & 882 & 54.8 (46.4 to 62.9 ) & 44.3 (40.4 to 48.3 ) & 0.026 \\
\hline South Africa & 2016 & 289 & 66.9 (56.4 to 75.9$)$ & 68.9 (58.9 to 77.5$)$ & 0.769 \\
\hline Zambia & $2013 / 2014$ & 2439 & 56.8 (52.2 to 61.3$)$ & 25.6 (22.9 to 28.6$)$ & $<0.001$ \\
\hline Zimbabwe & 2015 & 1064 & 0.0 & 0.0 & $\mathrm{n} / \mathrm{a}$ \\
\hline Total & 2010-2018 & 26241 & 52.8 (51.1 to 54.4$)$ & 40.7 (39.7 to 41.7$)$ & $<0.001$ \\
\hline
\end{tabular}

n/a, not applicable.

to health facilities. Sex of child was either male or female while birth order ranged from one (1) to six (6) or more. Maternal age was measured in completed years categorised into 5-year interval (15-19, 20-24, 25-29, 30-34, 35-39, 40-44, 45-49); education was captured as no education, primary, secondary and higher; wealth quintile was grouped as poorest, poorer, poor, richer and richest; occupation was measured as not working or working; distance to health facility was either not a big problem/no problem or a big problem; and finally health insurance subscription status was either yes (ie, subscribed) or no (ie, not subscribed).

\section{Analytical procedure}

The descriptive summaries of countries by year of survey, sample size and the prevalence of full immunisation by place of residence were presented in table 2. Similarly, a pooled analysis of the proportion of children who were fully immunised by residential status with respect to each of the covariates were presented in table 3 . A $\chi^{2}$ test of association was conducted to investigate if there exist a difference between the maternal and child characteristics by place of residence (table 4 ). The proportion of children aged 12-23 months with full immunisation status across the 23 countries was presented in figure 1. For the inferential analysis, we fitted a Poisson regression with robust standard errors to explore the predictors and direction of full immunisation status with respect to the covariates (table 5). In the final analysis, a multivariate non-linear decomposition model, ${ }^{18}$ which is similar to the Fairlie and Blinder-Oaxaca was employed to decompose the disparity in immunisation status due to residential status (table 6). This technique was used to evaluate the variation in full immunisation status between rural and urban children and to identify the contribution of each covariates to the explained immunisation variation between rural and urban children. The multivariate decomposition analysis was weighted, and other analyses were conducted using Stata software V.15.0 and adjusted for the complex survey design. The variance inflation factor (VIF) was used to check for the presence of multicollinearity which showed no evidence of multicollinearity (mean VIF=2.98, maximum=3.40, minimum=1.04). 
Table 3 Weighted full immunisation coverage by explanatory variables $(n=26241)$

\begin{tabular}{|c|c|c|c|c|}
\hline \multirow[b]{3}{*}{ Variables } & \multirow[b]{3}{*}{ Level } & \multicolumn{2}{|c|}{ Full immunisation coverage } & \multirow[b]{3}{*}{ P value } \\
\hline & & \multirow{2}{*}{$\begin{array}{l}\text { No } \\
\mathrm{n}(\%)\end{array}$} & \multirow{2}{*}{$\begin{array}{l}\text { Yes } \\
\mathrm{n}(\%)\end{array}$} & \\
\hline & & & & \\
\hline \multirow[t]{2}{*}{ Residence } & Urban & 3814 (47.2) & $4263(52.8)$ & $<0.001$ \\
\hline & Rural & 10764 (59.3) & 7399 (40.7) & \\
\hline \multicolumn{5}{|l|}{ Child factors } \\
\hline \multirow[t]{2}{*}{ Sex } & Male & 7300 (55.2) & $5936(44.8)$ & 0.780 \\
\hline & Female & 7278 (56.0) & 5727 (44.0) & \\
\hline \multirow[t]{6}{*}{ Birth order } & 1 & $2842(50.8)$ & 2757 (49.2) & $<0.001$ \\
\hline & 2 & $2556(51.7)$ & 2388 (48.3) & \\
\hline & 3 & 2350 (55.2) & 1905 (44.8) & \\
\hline & 4 & 1941 (55.9) & $1533(44.1)$ & \\
\hline & 5 & 1525 (58.2) & 1095 (41.8) & \\
\hline & $6+$ & 3363 (62.9) & 1985 (37.1) & \\
\hline \multicolumn{5}{|l|}{ Maternal factors } \\
\hline \multirow[t]{7}{*}{ Age } & $15-19$ & 1189 (61.1) & 757 (38.9) & $<0.001$ \\
\hline & $20-24$ & 3418 (54.2) & 2887 (45.8) & \\
\hline & $25-29$ & 3952 (54.6) & 3285 (45.4) & \\
\hline & $30-34$ & 2979 (54.8) & 2457 (45.2) & \\
\hline & $35-39$ & 1980 (55.6) & $1580(44.4)$ & \\
\hline & $40-44$ & $843(60.1)$ & 559 (39.9) & \\
\hline & $45-49$ & 217 (61.2) & 137 (38.8) & \\
\hline \multirow[t]{4}{*}{ Education } & No education & 5768 (60.3) & 3796 (39.7) & $<0.001$ \\
\hline & Primary & 5067 (55.4) & $4082(44.6)$ & \\
\hline & Secondary & 3369 (51.1) & 3226 (48.9) & \\
\hline & Higher & 374 (40.2) & 558 (59.8) & \\
\hline \multirow[t]{5}{*}{ Wealth quintile } & Poorest & 3801 (65.0) & 2046 (35.0) & $<0.001$ \\
\hline & Poorer & 3375 (60.7) & 2184 (39.3) & \\
\hline & Poor & 2943 (55.5) & 2363 (44.5) & \\
\hline & Richer & 2639 (52.2) & 2418 (47.8) & \\
\hline & Richest & $1821(40.7)$ & 2652 (59.3) & \\
\hline \multirow[t]{2}{*}{ Occupation } & Not working & 4969 (60.4) & 3252 (39.6) & $<0.001$ \\
\hline & Working & 9609 (53.3) & 8411 (46.7) & \\
\hline \multirow[t]{2}{*}{ Distance to health facility } & Not a big problem/no problem & 8015 (50.9) & 7731 (49.1) & $<0.001$ \\
\hline & A big problem & $6564(62.5)$ & 3931 (37.5) & \\
\hline \multirow[t]{2}{*}{ Sex of household head } & Male & $11516(55.8)$ & $9128(44.2)$ & 0.717 \\
\hline & Female & $3063(54.7)$ & $2534(45.3)$ & \\
\hline \multirow[t]{2}{*}{ Health insurance } & No & $13742(56.5)$ & $10598(43.5)$ & $<0.001$ \\
\hline & Yes & $836(44.0)$ & $1064(56.0)$ & \\
\hline
\end{tabular}

${ }^{*} \mathrm{p}<0.05$.

The Inner-City Fund International further ensures that the procedures of DHS are consistent with the regulations for the respect of human subjects as recommended by the US Department of Health and Human Services. Comprehensive information about the ethical protocols is accessible through http://goo. gl/ny8T6X. Authors sought and obtained permission to use the data from the Measure DHS Programme after our intent for the data was accessed.

\section{Patient and public involvement}

Patients and the public were not involved in the design and conduct of this research. 
Table 4 Weighted frequencies of explanatory variables by residence $(n=26241)$

\begin{tabular}{|c|c|c|c|c|}
\hline \multirow[b]{3}{*}{ Variables } & \multirow[b]{3}{*}{ Level } & \multicolumn{2}{|l|}{ Residence } & \multirow[b]{3}{*}{$P$ value* } \\
\hline & & Urban & Rural & \\
\hline & & $\mathrm{n}(\%)$ & n (\%) & \\
\hline \multirow[t]{2}{*}{ Child's sex } & Male & 4172 (51.6) & 9063 (49.9) & 0.245 \\
\hline & Female & 3905 (48.4) & $9100(50.1)$ & \\
\hline \multirow[t]{6}{*}{ Birth order } & 1 & $2156(26.7)$ & 3443 (19.0) & $<0.001$ \\
\hline & 2 & 1857 (23.0) & 3087 (17.0) & \\
\hline & 3 & 1470 (18.2) & 2785 (15.3) & \\
\hline & 4 & $1022(12.6)$ & 2453 (13.5) & \\
\hline & 5 & 659 (8.2) & 1961 (10.8) & \\
\hline & $6+$ & $914(11.3)$ & 4434 (24.4) & \\
\hline \multirow[t]{7}{*}{ Age } & $15-19$ & $549(6.8)$ & $1397(7.7)$ & $<0.001$ \\
\hline & 20-24 & 1929 (23.9) & $4376(24.1)$ & \\
\hline & $25-29$ & 2353 (29.1) & 4884 (26.9) & \\
\hline & $30-34$ & 1755 (21.7) & 3681 (20.3) & \\
\hline & $35-39$ & $1083(13.4)$ & 2477 (13.6) & \\
\hline & $40-44$ & $351(4.3)$ & $1051(5.8)$ & \\
\hline & $45-49$ & $58.2(0.7)$ & $296(1.63)$ & \\
\hline \multirow[t]{4}{*}{ Education } & No education & 1597 (19.8) & 7967 (43.9) & $<0.001$ \\
\hline & Primary & 2178 (27.0) & $6971(38.4)$ & \\
\hline & Secondary & 3540 (43.8) & 3055 (16.8) & \\
\hline & Higher & $763(9.4)$ & $169(0.9)$ & \\
\hline \multirow[t]{5}{*}{ Wealth quintile } & Poorest & $441(5.5)$ & 5406 (29.8) & $<0.001$ \\
\hline & Poorer & $500(6.2)$ & 5058 (27.8) & \\
\hline & Poor & 949 (11.8) & 4357 (24.0) & \\
\hline & Richer & 2440 (30.2) & 2616 (14.4) & \\
\hline & Richest & 3747 (46.4) & $726(4.0)$ & \\
\hline \multirow[t]{2}{*}{ Occupation } & Not working & 2781 (34.4) & $5440(30.0)$ & $<0.001$ \\
\hline & Working & 5297 (65.6) & $12723(70.0)$ & \\
\hline \multirow[t]{2}{*}{ Distance to health facility } & Not a big problem/No problem & $6236(77.2)$ & $9510(52.4)$ & $<0.001$ \\
\hline & A big problem & $1842(22.8)$ & $8653(47.6)$ & \\
\hline \multirow[t]{2}{*}{ Sex of household head } & Male & $6142(76.0)$ & $14501(79.8)$ & $<0.001$ \\
\hline & Female & $1935(24.0)$ & $3662(20.2)$ & \\
\hline \multirow[t]{2}{*}{ Health insurance } & No & $13742(94.3)$ & $10598(90.9)$ & $<0.001$ \\
\hline & Yes & $836(5.7)$ & $1064(9.1)$ & \\
\hline
\end{tabular}

${ }^{*} \mathrm{p}<0.05$

\section{RESULTS}

\section{Descriptive results}

The sample size ranged between 109 children in Lesotho to 2439 children in Zambia (table 2). More than half of children in urban settings were fully immunised $(52.8 \%)$ while nearly 6 out of 10 children were not fully immunised in rural locations $(59.3 \%)$ as shown in table 3.

There was no significant difference in the proportion of males with full immunisation compared with females with full immunisation ( $44.8 \%$ vs $44.0 \%$; $\mathrm{p}=0.780$ ). Full immunisation was prevalent among children of first birth order $(49.2 \%)$ and lowest among those having sixth or higher birth order $(37.1 \%)$. A significant proportion of children born to women aged 20-24 were fully immunised $(45.8 \%)$ as well as those born to women with higher education (59.8\%). As regard wealth quintile, $59.3 \%$ of children that belonged to the richest household were fully immunised while $46.7 \%$ of children whose mothers were working were fully immunised. Nearly half of the children of women who reported that distance to health facility was not a problem or a big problem were fully immunised $(49.1 \%)$. There were no statistically significant differences between the sex (male vs female) of the head of household and full immunisation status of 


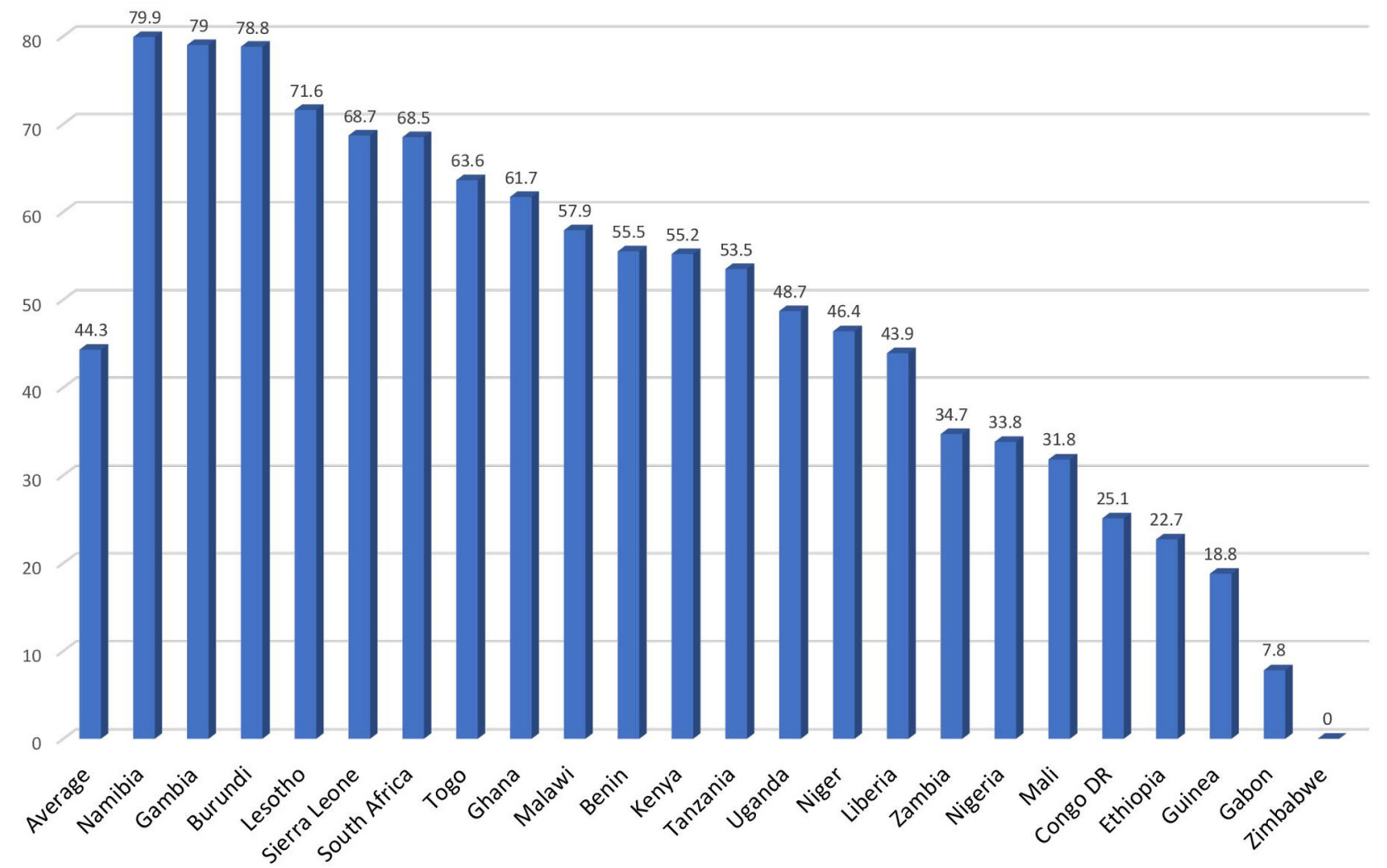

Figure 1 Full immunisation coverage per country.

a child $(44.2 \%$ vs $45.3 \%$; $\mathrm{p}=0.717$ ). Also, more than half of children whose mothers had health insurance were fully immunised $(56.0 \%)$.

The pooled analysis of the explanatory variables by residence presented in table 4 showed that $26.7 \%$ of children in the urban areas belonged to the first birth order compared with $19.0 \%$ in the rural areas whereas $24.4 \%$ of children in the rural areas were in the six or more-birth order compared with $11.3 \%$ in the rural areas. A higher proportion $(7.7 \%)$ of mothers in the rural areas were adolescent (15-19 years) compared with $6.8 \%$ in the urban settings. Similarly, there were striking differences in mothers' level of education and wealth status between place of residence. A higher proportion of mothers in the rural areas $(43.4 \%)$ had no formal education compared with $19.8 \%$ in the urban areas while $29.8 \%$ of mothers belonged to the poorest wealth quintile compared with $5.5 \%$ in the urban areas; whereas only $4.0 \%$ of mothers in the rural areas belong to the richest wealth quintile compared with $46.4 \%$ in the urban setting. There were more mothers in the rural areas compared with those in the urban settings that had a job $(70.0 \%$ vs $65.6 \%$; $\mathrm{p}<0.001)$. About half of the mothers who resided in rural areas had a big problem to access health facility due to distance compared with those in the urban locations ( $47.6 \%$ vs $22.5 \%$; $\mathrm{p}<0.001)$. In the urban areas, a higher proportion of household had a female head compared with rural areas $(24.2 \%$ vs $20.2 \%$; $<0.001)$ whereas in the rural areas a higher proportion of mothers had a health insurance scheme compared with those in the urban setting $(9.1 \%$ vs $5.7 \%$; $p<0.001)$

The full immunisation status of children across the 23 countries as indicated in figure 1 revealed an average of 44.3\% full immunisation status among children in SSA. Although, a large variation in full immunisation status was observed across countries, ranging from $0 \%-79.9 \%$. None of the children between 11 and 23 months in Zimbabwe had full immunisation, and only about one in 10 children were fully immunised in Gabon. Countries with high level of full immunisation compliance, where at least seven in 10 of the children had full immunisation include Burundi $(78.8 \%)$, Gambia (79.0\%) and Namibia (79.9\%). Although only Burundi had no statistically significant observed differences in urban-rural gap in full immunisation status ( 78.7 vs $77.8 ; \mathrm{p}=0.862$ ) among these countries. Other countries where no statistically significant exist in the urban-rural prevalence of full immunisation include Liberia (49.2 vs 43.3; $\mathrm{p}=0.384$ ), Malawi ( 56.0 vs 55.7; $\mathrm{p}=0.961)$, Sierraleone ( 63.2 vs $67.5 ; \mathrm{p}=0.380)$ and South Africa (66.9 vs $68.9 ; \mathrm{p}=0.769$ ) (table 2 ).

\section{Multivariable Poisson regression of full immunisation on the exposure variables}

Table 5 presents the relative risk of full immunisation coverage between urban and rural residents. Children who occupy sixth or higher birth orders had lower relative risk of full immunisation compared with first birth order children in urban (relative risk, RR $0.61 ; 95 \%$ CI 0.53 to 
Table 5 Multivariable poisson regression of full immunisation on the exposure variables

\begin{tabular}{|c|c|c|c|c|}
\hline & \multicolumn{2}{|c|}{ Urban } & \multicolumn{2}{|l|}{ Rural } \\
\hline & $\mathbf{R R}$ & $95 \% \mathrm{Cl}$ & $\mathbf{R R}$ & $95 \% \mathrm{Cl}$ \\
\hline \multicolumn{5}{|l|}{ Child factors } \\
\hline \multicolumn{5}{|l|}{ Child's sex } \\
\hline Male & Ref & Ref & Ref & Ref \\
\hline Female & 0.96 & 0.91 to 1.01 & 1.00 & 0.96 to 1.05 \\
\hline \multicolumn{5}{|l|}{ Birth order } \\
\hline 1 & Ref & Ref & Ref & Ref \\
\hline 2 & 0.94 & 0.88 to 1.01 & $0.88 \ddagger$ & 0.83 to 0.94 \\
\hline 3 & $0.81 \ddagger$ & 0.74 to 0.88 & $0.82 \ddagger$ & 0.76 to 0.89 \\
\hline 4 & $0.82 \ddagger$ & 0.74 to 0.91 & $0.79 \ddagger$ & 0.73 to 0.87 \\
\hline 5 & $0.74 \ddagger$ & 0.65 to 0.84 & $0.75 \ddagger$ & 0.68 to 0.83 \\
\hline $6+$ & $0.61 \ddagger$ & 0.53 to 0.70 & $0.69 \ddagger$ & 0.62 to 0.76 \\
\hline \multicolumn{5}{|l|}{ Maternal factors } \\
\hline \multicolumn{5}{|l|}{ Age } \\
\hline $15-19$ & $0.80 \dagger$ & 0.70 to 0.92 & $0.76 \ddagger$ & 0.68 to 0.85 \\
\hline $20-24$ & $0.91^{*}$ & 0.84 to 0.98 & 0.96 & 0.89 to 1.02 \\
\hline $25-29$ & Ref & Ref & Ref & Ref \\
\hline $30-34$ & 1.06 & 0.98 to 1.15 & $1.07^{\star}$ & 1.01 to 1.15 \\
\hline $35-39$ & $1.15 \dagger$ & 1.04 to 1.26 & $1.10^{\star}$ & 1.02 to 1.19 \\
\hline $40-44$ & 0.99 & 0.82 to 1.18 & 1.10 & 0.98 to 1.23 \\
\hline $45-49$ & $1.37^{\star}$ & 1.03 to 1.83 & 1.04 & 0.86 to 1.25 \\
\hline \multicolumn{5}{|l|}{ Education } \\
\hline No education & Ref & Ref & Ref & Ref \\
\hline Primary & $1.14 \dagger$ & 1.04 to 1.24 & 1.03 & 0.98 to 1.08 \\
\hline Secondary & 0.98 & 0.90 to 1.07 & 1.01 & 0.94 to 1.07 \\
\hline Higher & 0.97 & 0.86 to 1.09 & 0.95 & 0.77 to 1.16 \\
\hline \multicolumn{5}{|l|}{ Wealth quintile } \\
\hline Poorest & Ref & Ref & Ref & Ref \\
\hline Poorer & 0.84 & 0.69 to 1.02 & $1.11 \dagger$ & 1.04 to 1.18 \\
\hline Poor & 0.93 & 0.79 to 1.11 & $1.23 \ddagger$ & 1.16 to 1.31 \\
\hline Richer & 0.95 & 0.82 to 1.11 & $1.28 \ddagger$ & 1.20 to 1.38 \\
\hline Richest & $1.19^{*}$ & 1.02 to 1.38 & $1.32 \ddagger$ & 1.18 to 1.47 \\
\hline \multicolumn{5}{|l|}{ Occupation } \\
\hline Not working & Ref & Ref & Ref & Ref \\
\hline Working & 1.02 & 0.96 to 1.09 & $1.29 \ddagger$ & 1.22 to 1.36 \\
\hline \multicolumn{5}{|c|}{ Distance to health facility } \\
\hline $\begin{array}{l}\text { Not a big } \\
\text { problem/no } \\
\text { problem }\end{array}$ & Ref & Ref & Ref & Ref \\
\hline
\end{tabular}

A big problem $0.85 \ddagger 0.79$ to $0.92 \quad 0.85 \ddagger \quad 0.81$ to 0.89

Sex of household head

\begin{tabular}{lllll} 
Male & Ref & Ref & Ref & Ref \\
Female & 0.96 & 0.89 to 1.02 & 1.05 & 0.99 to 1.10 \\
Health insurance & & & & \\
No & Ref & Ref & Ref & Ref \\
\hline
\end{tabular}

Continued
Table 5 Continued

\begin{tabular}{llllll} 
& \multicolumn{2}{l}{ Urban } & & \multicolumn{2}{l}{ Rural } \\
\cline { 2 - 3 } \cline { 5 - 6 } & $\mathbf{R R}$ & $\mathbf{9 5 \%} \mathbf{C l}$ & & $\mathbf{R R}$ & $\mathbf{9 5 \%} \mathbf{C l}$ \\
\hline Yes & 0.94 & 0.87 to 1.0 & & $1.34^{* \star *}$ & 1.25 to 1.43 \\
\hline
\end{tabular}

${ }^{*} \mathrm{P}<0.05$.

$+P<0.01$

$\ddagger \mathrm{P}<0.001$.

Ref, reference category; RR, relative risk.

0.70 ) and rural (RR $0.69 ; 95 \%$ CI 0.62 to 0.76 ) settings. Children of women aged 45-49 had lower relative risk in urban (RR 0.80; 95\% CI 0.70 to 0.92) and rural (RR 0.76; $95 \%$ CI 0.68 to 0.85 ) locations compared with children of women aged 25-29. Among urban residents, the highest relative risk was recorded among children of 45-49 aged women (RR 1.37; 95\% CI 1.03 to 1.83 ).

Relative to children of women without formal education, children of primary educated women in urban locations had higher relative risk of full immunisation (RR 1.14; $95 \%$ CI 1.04 to 1.24) same as children of richest urban women compared with those having poorest mothers or caregivers (RR 1.19; 95\% CI 1.02 to 1.38). In the case of rural children, relative risk was high among children whose mothers/caregivers were richest (RR 1.32; $95 \%$ CI 1.18 to 1.47 ). Similarly, relative risk of full immunisation was higher among children whose mothers were working (RR 1.29; 95\% CI 1.22 to 1.36 ) or had health insurance (RR 1.34; 95\% CI 1.25 to 1.43 ) in rural locations compared with children whose mothers were neither working nor had health insurance respectively. Meanwhile, children whose mothers/caregivers indicated that distance to health facility was a big problem had lower risk ratio of full immunisation (RR 0.85; 95\% CI 0.81 to 0.89 ) in urban locations.

\section{Decomposition of disparity in full immunisation coverage between rural and urban residence}

Decomposition of the disparity in full immunisation coverage between rural and urban residence revealed that $76.5 \%$ variation is attributable to differences in child and maternal characteristics (table 6). Household wealth was an important component contributing to the ruralurban gap. Specifically, richest wealth status substantially accounted for immunisation disparity (35.7\%). First and sixth birth orders contributed $7.3 \%$ and $14.9 \%$, respectively, towards the disparity while $7.9 \%$ was attributable to distance to health facility.

\section{DISCUSSION}

This study examined full childhood immunisation gap between rural and urban populace in SSA. The study revealed variation in full immunisation in favour of urban children. Most children of higher birth order were in rural locations. No child was fully immunised in Zimbabwe and this may be aligned with the immunisation funding gap in the country. ${ }^{19}$ The over-reliance on donor 
BMJ Global Health

Table 6 Multivariate decomposition of child and maternal factors associated with full immunisation inequality between rural and urban residence

\begin{tabular}{|c|c|c|c|c|}
\hline \multirow[b]{2}{*}{ Characteristics } & \multicolumn{2}{|c|}{ Difference due to characteristics (E) } & \multicolumn{2}{|c|}{ Difference due to coefficients (C) } \\
\hline & Coefficient & Percentage (\%) & Coefficient & Percentage (\%) \\
\hline$\%$ total explained disparity & & 76.47 & & 23.53 \\
\hline \multicolumn{5}{|l|}{ Child factors } \\
\hline \multicolumn{5}{|l|}{ Child's sex } \\
\hline Male & 0.00018 & 0.16 & 0.00576 & 4.78 \\
\hline Female & 0.00019 & 0.16 & -0.00578 & -4.80 \\
\hline \multicolumn{5}{|l|}{ Birth order } \\
\hline 1 & $-0.00880^{\star \star \star}$ & 7.31 & 0.00483 & 4.01 \\
\hline 2 & $-0.00484^{* \star *}$ & 4.03 & 0.00788 & 6.55 \\
\hline 3 & -0.00013 & -0.11 & -0.00091 & -0.76 \\
\hline 4 & -0.00001 & -0.01 & 0.0198 & 1.65 \\
\hline 5 & $-0.00143^{\star \star}$ & 1.18 & -0.00187 & -1.56 \\
\hline $6+$ & $-0.01799^{\star \star \star}$ & 14.94 & -0.01544 & -12.82 \\
\hline \multicolumn{5}{|l|}{ Maternal factors } \\
\hline \multicolumn{5}{|l|}{ Age } \\
\hline $15-19$ & $0.00121^{\star \star \star}$ & 1.01 & -0.00147 & -1.22 \\
\hline $20-24$ & $0.00015^{\star \star}$ & 0.13 & $-0.01200^{*}$ & -9.97 \\
\hline $25-29$ & -0.00032 & -0.27 & -0.00422 & -3.51 \\
\hline $30-34$ & $0.00031^{\star *}$ & 0.26 & -0.00221 & -1.84 \\
\hline $35-39$ & $-0.00014^{\star \star}$ & -0.12 & 0.00263 & 2.18 \\
\hline $40-44$ & 0.00015 & 0.12 & -0.00289 & -2.40 \\
\hline $45-49$ & $0.00135^{\star}$ & -1.12 & $0.00206^{*}$ & 1.70 \\
\hline \multicolumn{5}{|l|}{ Education } \\
\hline No education & 0.00223 & 1.85 & 0.00364 & -3.03 \\
\hline Primary & $-0.00670^{\star \star \star}$ & -5.57 & $-0.01793^{*}$ & 14.89 \\
\hline Secondary & -0.00569 & -4.73 & 0.00378 & -3.14 \\
\hline Higher & 0.00241 & -2.00 & -0.00015 & 0.12 \\
\hline \multicolumn{5}{|l|}{ Wealth quintile } \\
\hline Poorest & -0.00218 & -1.81 & $0.02299^{\star \star}$ & 19.10 \\
\hline Poorer & $0.01464^{*}$ & 12.16 & -0.01040 & -8.64 \\
\hline Poor & 0.00297 & 2.47 & -0.00878 & -7.29 \\
\hline Richer & -0.00294 & -2.44 & $-0.00748^{\star \star}$ & -6.21 \\
\hline Richest & $0.04304^{\star \star \star}$ & 35.74 & $0.00194^{*}$ & 1.61 \\
\hline \multicolumn{5}{|l|}{ Occupation } \\
\hline Not working & -0.00027 & -0.23 & $-0.01306^{\star \star \star}$ & 10.85 \\
\hline Working & -0.00027 & -0.23 & $0.03056^{\star * \star}$ & -25.38 \\
\hline \multicolumn{5}{|l|}{ Distance to health facility } \\
\hline Not a big problem/no problem & $-0.00957^{\star \star \star}$ & 7.94 & -0.00217 & 1.79 \\
\hline A big problem & $-0.00957^{\star \star \star}$ & 7.94 & 0.00197 & -1.63 \\
\hline \multicolumn{5}{|l|}{ Sex of household head } \\
\hline Male & -0.00042 & -0.35 & $-0.01640^{\star}$ & 13.61 \\
\hline Female & -0.00042 & -0.35 & $-0.00414^{*}$ & -3.44 \\
\hline \multicolumn{5}{|l|}{ Health insurance } \\
\hline No & -0.00097 & -0.81 & $-0.08356^{\star \star \star}$ & 69.39 \\
\hline
\end{tabular}


Table 6 Continued

\begin{tabular}{cllllll}
\hline \multirow{2}{*}{ Characteristics } & \multicolumn{2}{l}{ Difference due to characteristics (E) } & & \multicolumn{3}{l}{ Difference due to coefficients (C) } \\
\cline { 2 - 3 } \cline { 5 - 6 } & Coefficient & Percentage (\%) & & Coefficient & Percentage (\%) \\
\hline Yes & -0.00097 & -0.81 & $-0.00469^{\star * \star}$ & -3.89 \\
\hline
\end{tabular}

${ }^{*} p<0.05,{ }^{* *} p<0.01,{ }^{* *} p<0.001$.

partners needs to be reconsidered in order to ensure that most children, if not all, are fully immunised. Further, a number of contexual factors may also account for this finding from Zimbabwe. For instance, the freezing of posts within the health sector of Zimbabwe has adversely affected management of Expanded Programme on Immunisation (EPI) ${ }^{19}$ Primary Care Nurses who operate the health centres in rural locations are inadequate, possess limited skills and knowledge in EPI, and receive little payments which do not motivate them enough. ${ }^{19}$ Besides, geographical access to health centres is a challenge to some women as some of them walk $30 \mathrm{~km}$ to the nearest health facility. Intermittent shortage of essential medicines has also been reported as well as hesitancy and refusal by women. ${ }^{19} 20$

Since most of these 23 countries have health insurance schemes that are propoor and absorb immunisation cost, ${ }^{21-24}$ it was anticipated that full immunisation will be generally high across the countries. Yet, the wide variation in full immunisation status is suggestive that context-specific factors sometimes transcend the 'cost component'. In Namibia, for instance, where most children were fully immunised $(79.9 \%)$, evidence indicates that even mothers in rural locations are knowleageable about the implications of missed immunisation on their children and are willing to access vaccines for their children amidst transportation cost and other barriers. ${ }^{25}$ Other countries with high proportion of fully immunised children such as Burundi benefit consistently from central government's commitment and funding from external bodies such as the GAVI Alliance and the Measles and Rubella Initiative. ${ }^{26}$ These context-specific variations must, therefore, be appreciated by governments of subSaharan African countries and private entities aiming to improve full immunisation coverage in SSA.

The study revealed that factors contributing to this gap were maternal factors such as age, wealth quintile, occupation, distance to health facility and health insurance subscription. Birth order, however, was a child factor that made significant contribution towards the variation in full immunisation. The observed variation is not unexpected in light of the high concentration of health facilites and health personnel in urban locations across SSA. For instance, in the case of Sierra Leone, over $70 \%$ of surgeons are concetrated in the capital of the country, Freetown, and between 2005 and 2011, the doctorpatient ratio for the sectors hosting the capital rose from 0.07 to 0.12 per 1000 population. Within the same period, an increase from 0.030 to 0.05 occurred in the rural locations (eg, Koinadugu) per 1000 population. ${ }^{27}$ Analogous observation was made for the patient-nurse ratio. ${ }^{28}$ Similarly in Mali, $55 \%$ of healthcare providers operate within its capital of Bamako while the remaining $45 \%$ cater for the health needs of all persons outside the captial. ${ }^{29}$

Literature indicates that rural residents increasingly have significantly lower utilisation of public health services across several low-income and middle-income countries. $^{30} 31$ Ability of sub-Saharan African countries to mitigate this deep-seated rural-urban disparity may certainly address the current disparity and thereby enhance the prospects of SSA to achieve the 3.2 SDG target of plummeting under-five mortality to at worst 25 per 1000 live births, respectively. ${ }^{5}$ A promising strategy in achieving this may be marshalling resources to knit childhood immunisation services with the primary healthcare concept in order for rural residents to access immunisation with the least setbacks such as covering long nonmotorable distances and associated costs. This could motivate rural residents to ensure that their children obtain all the full immunisation doses within the recommended time frame.

Birth order of 6 or higher appeared to intensify the disparity in full immunisation status. This observation coincides with evidence from a recent study from Cameroon where through multinomial probit model, authors noticed that birth order has a negative and highly significant effect on full and timely childhood immunisation. $^{32}$ Maternal experience and information received by the women during antenatal care visits of their pervious births could partly account for this observation. ${ }^{33}$ While first time mothers are less confident, and perceive themselves as requiring much support, a woman with multiple births may be less concerned about childhood ailments that have been exhibited by her child in the past. ${ }^{34}$ Maternal health workforce of SSA may be able to neutralise this disparity by acknowledging that anxieties and maternal healthcare utilisation levels vary by parity. Among the numerous strategies to improve the situation include targeting and educating multiparous women to appreciate that all children who miss any dose of immunisation stand a chance of ill health conditions. This may serve as a cue or prompt for them to seek the full immunisation for all their children.

Full immunisation status was aligned with richest wealth status. Even in countries where health insurance and free maternal healthcare exist like Ghana, ${ }^{35} 36$ women incur out of pocket expenses to cover transportation, laboratory and other services. Consequently, richest women have some leverage over poorest women. ${ }^{37}$ Moreover, wealth is a pathway to empowerment ${ }^{38}$ and it is well established 
in the literature that once a woman is empowered, it is more probable that she will use maternal healthcare. ${ }^{39} 40$ A poor woman may know and acknowledge the essences to get her child immunised in full, but her passion may remain a mirage if the requisite financial capacity is non-existent.

Distance to health facility was a significant indicator for disparity in full immunisation. After birth, a woman may require a substantial amount of time to recover and this period varies subject to a number of factors. For instance, a woman who underwent a caesarean section may require more time than a woman who had a normal vaginal birth. ${ }^{41}$ Owing to these factors, covering a long distance to immunise one's child may be difficult for most women if not impossible. Distance has been noted as a cardinal determiner of maternal healthcare utilisation and in the perspective of Thaddeus, Maine, ${ }^{42}$ it is the second leading delay leading to maternal and newborn ill health and deaths in low-income and middle-income countries as espoused in their three delays model.

\section{Strengths and limitations}

Findings from the study are supported by large datasets covering 23 countries in SSA. The data were gathered following a common internationally acceptable methodological procedure. Due to the representative nature of the survey, the findings are representative of included countries and generalisable to women of reproductive age. In spite of these strengths, the survey is crosssectional in nature and as such causal inference cannot be made. Also, the sample size is generally not large for some of the countries and may allow for a wider CI for the prevalence of full immunisation.

\section{CONCLUSION}

The study has illustrated that rural-urban disparity in full childhood immunisation exist in favour of urban children. Factors that explain this partly include child's birth order, maternal age, wealth quintile, occupation and distance to health facility. Subregional, national and community-level interventions to obviate this disparity should taregt poorest women, distance to health facilities and women who are not working. Moreover, sub-Saharan African countries with very low full immunisation rate like Zimbabwe and Gabon may understudy countries with high coverage like Namibia and Gambia and adopt some of the interventions that have culminated in high full immunisation rate. However, much caution needs to be taken with respect to contexutal and cultural diversities.

\footnotetext{
Author affiliations

${ }^{1}$ School of Public Health, Faculty of Health, University of Technology Sydney, Sydney, New South Wales, Australia

${ }^{2}$ Institute for Advanced Medical Research and Training, College of Medicine, University of Ibadan, Ibadan, Nigeria

${ }^{3}$ College of Public Health, Medical and Veterinary Sciences, James Cook University, Townsville, Queensland, Australia

${ }^{4}$ Department of Population and Health, University of Cape Coast, Cape Coast, Ghana
}

${ }^{5}$ School of International Development and Global Studies, University of Ottawa, Ottawa, Ontario, Canada

${ }^{6}$ The George Institute for Global Health, Imperial College London, London, UK

Twitter Edward Kwabena Ameyaw @edward_ameyaw and Sanni Yaya @SannietYaya

Acknowledgements The authors thank the MEASURE DHS project for their support and for free access to the original data.

Contributors SY contributed to the study design and conceptualisation. EKA drafted the initial draft and performed the analysis with the help of YOK. BOA and A-AS provided technical support and critically reviewed the manuscript for its intellectual content. SY had final responsibility to submit for publication. All authors read and amended drafts of the paper and approved the final version.

Funding The authors have not declared a specific grant for this research from any funding agency in the public, commercial or not-for-profit sectors.

Competing interests Sanni Yaya is associate editor with this journal.

Patient consent for publication No consent to publish was needed for this study as we did not use any details, images or videos related to individual participants. In addition, data used are available in the public domain.

Ethics approval and consent to participate The DHS survey protocols and procedures are scrutinised and approved by the ethics committee of ORC Macro and partner organisations of participating countries.

Provenance and peer review Not commissioned; externally peer reviewed.

Data availability statement Data are available in a public, open access repository. Data for this study were sourced from Demographic and Health surveys (DHS) and available here: http://dhsprogram.com/data/available-datasets.cfm.

Supplemental material This content has been supplied by the author(s). It has not been vetted by BMJ Publishing Group Limited (BMJ) and may not have been peer-reviewed. Any opinions or recommendations discussed are solely those of the author(s) and are not endorsed by BMJ. BMJ disclaims all liability and responsibility arising from any reliance placed on the content. Where the content includes any translated material, BMJ does not warrant the accuracy and reliability of the translations (including but not limited to local regulations, clinical guidelines, terminology, drug names and drug dosages), and is not responsible for any error and/or omissions arising from translation and adaptation or otherwise.

Open access This is an open access article distributed in accordance with the Creative Commons Attribution Non Commercial (CC BY-NC 4.0) license, which permits others to distribute, remix, adapt, build upon this work non-commercially, and license their derivative works on different terms, provided the original work is properly cited, appropriate credit is given, any changes made indicated, and the use is non-commercial. See: http://creativecommons.org/licenses/by-nc/4.0/.

\section{ORCID iDs}

Edward Kwabena Ameyaw http://orcid.org/0000-0002-6617-237X

Bright Opoku Ahinkorah http://orcid.org/0000-0001-7415-895X

Abdul-Aziz Seidu http://orcid.org/0000-0001-9734-9054

Sanni Yaya http://orcid.org/0000-0002-4876-6043

\section{REFERENCES}

1 Wang $\mathrm{H}$, Abajobir AA, Abate $\mathrm{KH}$, et al. Global, regional, and national under-5 mortality, adult mortality, age-specific mortality, and life expectancy, 1970-2016: a systematic analysis for the global burden of disease study 2016. The Lancet 2017;390:1084-150.

2 McGovern ME, Canning D. Vaccination and all-cause child mortality from 1985 to 2011: global evidence from the demographic and health surveys. Am J Epidemiol 2015;182:791-8.

3 Griggs D, Stafford-Smith M, Gaffney O, et al. Policy: sustainable development goals for people and planet. Nature 2013:495:305-7.

4 Obasohan PE, Mustapha MA, Makada A, et al. Evaluating the reasons for partial and Non-immunization of children in Wushishi local government area, niger state, Nigeria: methodological comparison. Afr J Reprod Health 2018;22:113-22.

5 United Nations. Transforming our World: the 2030 agenda for sustainable development. Geneva: United Nations, 2015.

6 WHO. Ministerial conference on immunization in Africa. historical commitment from Africa heads of states to advance immunization in Africa, 2017. Available: http://immunizationinafrica2016.org/releases/ 
2017/1/31/historic-commitment-from-african-heads-of-state-toadvance-immunization-in-africa

7 WHO. Experts caution against stagnation of immunization coverage in Africa, 2019. Available: https://www.afro.who.int/news/expertscaution-against-stagnation-immunization-coverage-africa

8 Cooper S, Betsch C, Sambala EZ, et al. Vaccine hesitancy - a potential threat to the achievements of vaccination programmes in Africa. Hum Vaccin Immunother 2018;14:2355-7.

9 Bangura JB, Xiao S, Qiu D, et al. Barriers to childhood immunization in sub-Saharan Africa: a systematic review. BMC Public Health 2020;20:1108.

10 Adetokunboh OO, Uthman OA, Wiysonge CS. Non-Uptake of childhood vaccination among the children of HIV-infected mothers in sub-Saharan Africa: a multilevel analysis. Hum Vaccin Immunother 2018:14:2405-13.

11 Oleribe O, Kumar V, Awosika-Olumo A, et al. Individual and socioeconomic factors associated with childhood immunization coverage in Nigeria. Pan Afr Med J 2017;26:220.

12 Wiysonge CS, Uthman OA, Ndumbe PM, et al. Individual and contextual factors associated with low childhood immunisation coverage in sub-Saharan Africa: a multilevel analysis. PLoS One 2012;7:e37905.

13 Adamu AA, Uthman OA, Sambala EZ, et al. Rural-Urban disparities in missed opportunities for vaccination in sub-Saharan Africa: a multi-country decomposition analyses. Hum Vaccin Immunother 2019;15:1191-8.

14 Yaya S, Uthman OA, Okonofua F, et al. Decomposing the rural-urban gap in the factors of under-five mortality in sub-Saharan Africa? Evidence from 35 countries. BMC Public Health 2019;19:616.

15 Anyangwe SCE, Mtonga C. Inequities in the global health workforce: the greatest impediment to health in sub-Saharan Africa. Int $J$ Environ Res Public Health 2007;4:93-100.

16 Corsi DJ, Neuman M, Finlay JE, et al. Demographic and health surveys: a profile. Int J Epidemiol 2012;41:1602-13.

17 WHO. Immunization schedules - Africa, 2018. Available: http://www. vacfa.uct.ac.za/immunization-schedules-africa

18 Powers DA, Yoshioka H, Yun M-S. mvdcmp: multivariate decomposition for nonlinear response models. Stata $J$ 2011;11:556-76.

19 Ministry of Health and Child Care. Zimbabwe expanded programme on immunisation comprehensive multi year plan 2015-2019. Zimbabwe: Ministry of Health and Child Care, 2014.

20 Ministry of Health and Child Care, UNICEF. Factors influencing vaccine Hesitancy and immunization coverage in Zimbabwe: a rapid assessment, 2017. Available: https://www.google.com/url?sa=t\&rct= $j \& q=\& e s r c=s \&$ source $=$ web\& $c d=\& c a d=r j a \& u a c t=8 \& v e d=2 a h U K E w i$ P4oeHIYntAhXiWhUIHaPSDyMQFjAAegQIAxAC\&url=https\%3A\% 2F\%2Fwww.unicef.org\%2Fzimbabwe\%2Fmedia\%2F356\%2Ffile\% 2FFactors\%2520Influencing\%2520Vaccine\%2520Hesitancy\% 2520 and $\% 2520$ Immunization\%2520Coverage\%2520in\% 2520Zimbabwe.pdf\&usg=AOvVaw2m9WURDskKMqI5APX3G1Gw

21 Fenny AP, Yates R, Thompson R. Social health insurance schemes in Africa leave out the poor. Int Health 2018;10:1-3.

22 Carapinha JL, Ross-Degnan D, Desta AT, et al. Health insurance systems in five sub-Saharan African countries: medicine benefits and data for decision making. Health Policy 2011;99:193-202.

23 Olugbenga EO. Workable social health insurance systems in subSaharan Africa: insights from four countries. Africa Development 2017:42:147-75.

24 Dake FAA. Examining equity in health insurance coverage: an analysis of Ghana's National health insurance scheme. Int J Equity Health 2018;17:85.
25 Lifalaza A, Stern R, Ashipala DO. Perceptions of mothers and caregivers regarding the factors affecting low uptake of measles immunisation among children under 5 years in Nyangana district, Namibia. Glob J Health Sci 2018;10:74.

26 Gavi. Burundi introduces second dose of measles vaccine, 2020. Available: https://www.gavi.org/burundi-introduces-second-dose-ofmeasles-vaccine

27 Kingham TP, Kamara TB, Cherian MN, et al. Quantifying surgical capacity in Sierra Leone: a guide for improving surgical care. Arch Surg 2009;144:122-7.

28 Wurie H, Samai M, SJRfR W. Staffing the public health sector in Sierra Leone, 2005-11: findings from routine data analysis, 2012. Available: https://researchonline.Ishtm.ac.uk/2137768/1/czv006. pdf

29 Bridges from Bamako. Bamako, 1997 to 2012: what's changed? 2012. Available: https://bridgesfrombamako.com/2012/01/12/ bamako-1997

30 Khan MMH, Zanuzdana A, Kraemer A. Levels, trends and disparities in public-health-related indicators among reproductive-age women in Bangladesh by urban-rural and richest-poorest groups, 19932011. PLoS One 2013;8:e75261.

31 Reifsnider E, MS LH, Muennink P, et al. Learning public health nursing in urban, rural, and border counties of Texas. Fam Community Health 2004;27:282-90.

32 De Paul NKV. Birth order and demand for immunization for children under the age of five in Cameroon 2020, 2020. Available: https:// www.africaportal.org/publications/birth-order-and-demandimmunization-children-under-age-five-cameroon/

33 Anastasi E, Borchert M, Campbell OMR, et al. Losing women along the path to safe motherhood: why is there such a gap between women's use of antenatal care and skilled birth attendance? a mixed methods study in northern Uganda. BMC Pregnancy Childbirth 2015;15:287.

34 McLeish J, Harvey M, Redshaw M, et al. First-time mothers expectations and experiences of postnatal care in England. Qual Health Res 2020;30:1876-87.

35 National Health Insurance Authority (NHIA). National health insurance authority annualreport, Accra: 2013, 2020. Available: http://www.nhis.gov.gh/annualreports.aspx

36 Agbanyo R. Ghana's national health insurance, free maternal healthcare and facility-based delivery services. Afr Dev Rev 2020;32:27-41.

37 Sanogo N'doh Ashken, Yaya S. Wealth status, health insurance, and maternal health care utilization in Africa: evidence from Gabon. Biomed Res Int 2020;2020:4036830.

38 Yaya S, Uthman OA, Ekholuenetale M, et al. Women empowerment as an enabling factor of contraceptive use in sub-Saharan Africa: a multilevel analysis of cross-sectional surveys of 32 countries. Reprod Health 2018;15:214.

39 Sado L, Spaho A, Hotchkiss DR. The influence of women's empowerment on maternal health care utilization: evidence from Albania. Soc Sci Med 2014;114:169-77.

40 Pandey S, Lama G, Lee H. Effect of women's empowerment on their utilization of health services: A case of Nepal. Int Soc Work 2012;55:554-73

41 Kealy MA, Small RE, Liamputtong P. Recovery after caesarean birth: a qualitative study of women's accounts in Victoria, Australia. BMC Pregnancy Childbirth 2010;10:47.

42 Thaddeus S, Maine D. Too far to walk: maternal mortality in context. Soc Sci Med 1994;38:1091-110. 